\title{
Surface Modification of Titanium by Producing Ti/TiN Surface Composite Layers via FSP
}

\author{
Ali Shamsipur ${ }^{1} \cdot$ Seyed-Farshid Kashani-Bozorg $^{2} \cdot$ Abbas Zarei-Hanzaki $^{2}$
}

Received: 10 July 2016/Revised: 30 September 2016/Published online: 14 February 2017

(C) The Chinese Society for Metals and Springer-Verlag Berlin Heidelberg 2017

\begin{abstract}
In this paper, we report the use of blowing nitrogen gas for the successful fabrication of a composite layer composed of Ti/TiN on a substrate of commercially pure titanium (cp-2) using the friction stir processing technique. The prepared composite layer was characterized by X-ray diffraction, scanning electron microscopy and energy-dispersive $\mathrm{X}$-ray spectrometry. The maximum microhardness of the Ti/TiN composite reached $1024 \mathrm{HV}$, which is 6.4 times higher than that of the titanium substrate. The results of wear test indicated that the Ti/TiN composite layer possesses excellent abrasive and adhesive wear resistance because of the formation of the TiN and its high hardness.
\end{abstract}

\section{KEY WORDS: Friction stir processing; Surface composite; Titanium; TiN; Hardness; Wear resistance; X-} ray diffraction

\section{Introduction}

Titanium and its alloys possess a variety of excellent properties including high strength-to-weight ratio, good corrosion resistance and low toxicity. Nevertheless, titanium alloys possess poor tribological properties, such as poor abrasive and adhesive wear resistance and high coefficient of friction. Thus, it is normally required to improve their tribological properties by surface treatments [1-3]. In the past, a number of surface modification techniques have been developed to modify the surface properties of titanium [1]. Among these, the nitriding of titanium and titanium alloys has been investigated for

Available online at http://link.springer.com/journal/40195

Ali Shamsipur

shamsipur@aut.ac.ir

1 Department of Mining and Metallurgical Engineering, Amirkabir University of Technology, Tehran, Iran

2 School of Metallurgy and Materials Engineering, University College of Engineering, University of Tehran,

P.O. Box 11155-4563, Tehran, Iran many years, via diffusion and re-melting methods, and is used properly for protection against wear [4]. Diffusion methods, like gas nitriding, are independent of geometry of the samples and do not need especial equipment [5]. However, these methods require high temperatures and long time to complete the process. Meanwhile, although the re-melting methods, such as laser nitriding, provide an excellent metallurgical bond between surface layer and titanium substrate [6,7], they suffer from surface cracking and require special equipment.

In the past decade, researchers have paid an increasing attention to a new surface modification method called friction stir processing (FSP) for the preparation of surface composite layers. In this technique, a non-consumable rotating tool is inserted into a substrate and produces a severe plastically deformed zone. It is well established that the stir zone has a fine and equiaxed grains produced by dynamic re-crystallization [8]. Different composites have been prepared on titanium or other metals using FSP method [9-11]. Most of the composite and nano-composite surface layers produced by FSP have been made by incorporating a ceramic powder into a preformed groove on the surface of the substrate [12-16]. Lee et al. [12] 
applied FSP to incorporate 5-10 vol\% nano-sized $\mathrm{SiO}_{2}$ into an AZ61 Mg alloy matrix. They found that the nanoparticles can be uniformly dispersed after four FSP passes and decrease the grain size of the resulting composition, which results in nearly doubling the hardness of the base material. Recently, Shafiei-Zarghani et al. [13] reported the incorporation of nano-sized $\mathrm{Al}_{2} \mathrm{O}_{3}$ with 6082 aluminum alloy. The results revealed good dispersion of $\mathrm{Al}_{2} \mathrm{O}_{3}$ particles, reduced grain size of the $6082 \mathrm{Al}$ matrix and a significant increase in microhardness and wear resistance (2-3 times) of the $\mathrm{Al} / \mathrm{Al}_{2} \mathrm{O}_{3}$ surface nano-composites. In 2006, in a series of interesting FSP applications, Morisada et al. [14] successfully incorporated C60, multiwalled carbon nanotubes (MWCNTs) [15] and microsized SiC particles [16] in a magnesium alloy (AZ31). In all cases, they reported uniform dispersion of particles, decreased grain size and a subsequent significant increase in microhardness of the substrate (up to three times).

A novel approach in the application of FSP in the preparation of the composite layers on the surface of materials is the use of blowing active gases during the FSP procedure [17]. In this paper, we report the preparation of Ti/TiN surface composite layers through FSP of unalloyed titanium by blowing nitrogen gas on the interface of substrate and FSP tool. The microstructure of TiN at the base metal was observed by scanning electronic microscopy (SEM) and optical microscopy (OM), and a detailed phase characterization was undertaken mainly by X-ray diffraction (XRD) technique. Finally, the mechanical properties including microhardness and wear resistance of the surface composite layers have been evaluated in detail.

\section{Experimental}

Commercially pure (cp-2) titanium-rolled plate with a thickness of $6 \mathrm{~mm}$ was used as substrate, and a nitrogen gas with a purity of $99.8 \%$ was used as the blowing gas to supply the required nitrogen for preparation of composite layers.

A groove with a depth $\times$ width of $2 \mathrm{~mm} \times 2 \mathrm{~mm}$ was applied on the work pieces in order to blow the nitrogen gas between the rotating tool and the sample surface by a gas shrouding system. The FSP tool made of hardened H13 steel possessed a columnar shape ( $28 \mathrm{~mm}$ diameter) with a tungsten carbide pin (6 $\mathrm{mm}$ diameter, $3 \mathrm{~mm}$ length). The pin was inserted into the groove, and a constant tool rotating rate of $1250 \mathrm{rpm}$ and a travel speed of $35 \mathrm{~mm} \mathrm{m^{-1 }}$ were adopted. A tool tilt angle of $3^{\circ}$ was used to have a better control on the material flow with a fine nitrogen flow under the shoulder.

The stir zone temperature was measured just as passed by a tool using a K-type thermocouple, which was adjusted in the middle length of the titanium plate, $2 \mathrm{~mm}$ below the surface of the work plate. The temperature was recorded as a function of time.

Microstructural observations of the sample cross sections perpendicular to the tool traverse direction were carried out by OM and SEM (CAM Scan MV2300). The phase analysis was examined by XRD (Philips X'Pert), using $\mathrm{Cu}$ radiation from an angle of $20^{\circ}$ to $80^{\circ}(2 \theta)$, with a step size of $0.02^{\circ}$ and a counting time of $0.8 \mathrm{~s}$ per step. The microhardness was measured using a micro-Vickers hardness tester with a load of $200 \mathrm{~g}$ for $12 \mathrm{~s}$. The average microhardness measurements were taken along a line from the base material, transferring the entire stirred zone, to the surface.

Wear tests were made by a pin-on-disk tribometer, using cylindrical samples of $6 \mathrm{~mm}$ in diameter and $6 \mathrm{~mm}$ in height. The counterpart disks were made of AISI 52100 steel, with hardness of about $60 \mathrm{HRC}$ and surface roughness of $\mathrm{Ra}$ of $0.2 \mu \mathrm{m}$. The pin samples were polished with a 600 grade $\mathrm{SiC}$ paper. The wear tests were performed under dry sliding conditions for $1200 \mathrm{~m}$ at normal loads of 15,30 and $45 \mathrm{~N}$ with a linear speed of $0.3 \mathrm{~m} \mathrm{~s}^{-1}$. A series of tests at linear speeds of $0.1,0.3$ and $0.5 \mathrm{~m} \mathrm{~s}^{-1}$ with a normal load of $15 \mathrm{~N}$ were also carried out to examine the influence of sliding speed on the tribological properties.

The wear test specimens, cleaned with acetone, weighed to an accuracy of $\pm 1 \mathrm{mg}$ prior to and at end of the test. A stress sensor was used to determine the coefficient of friction between the pin specimen and the disk. The SEM and energy-dispersive X-ray spectrometry (EDS) were employed to inspect the worn surfaces after the tests.

\section{Results and Discussion}

The top surface of the samples showed no visible defects, such as voids and cracks. The color of the CP-Ti sample was assessed before and after nitriding. Before nitriding, the color was silver gray, while, after nitriding by FSP, the surface color was turned to a clear golden color. It is worth mentioning that the color of upper surface of FSPed Ti without nitrogen gas was gray. The transverse cross section of the sample is shown in Fig. 1, from which the thermomechanical affected zone (TMAZ) and the stir zone (SZ) of the process are visually observable. The light regions near the top surface and inside the SZ indicate the Ti/TiN composite islands. As is obvious from Fig. 1, no defect, such as pores and tunnels, is seen in the transverse cross section of the sample, indicating the accomplishment of a proper weld at the surface.

\subsection{XRD and Microstructures}

Figure 2 shows the XRD patterns of the transverse cross section of FSP nitrided sample. As is obvious, at a prefixed 


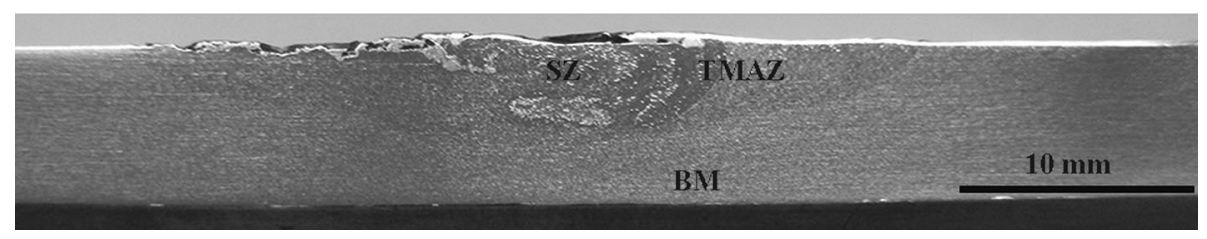

Fig. 1 Transverse cross section of the of Ti/TiN surface composite layer produced by FSP sample

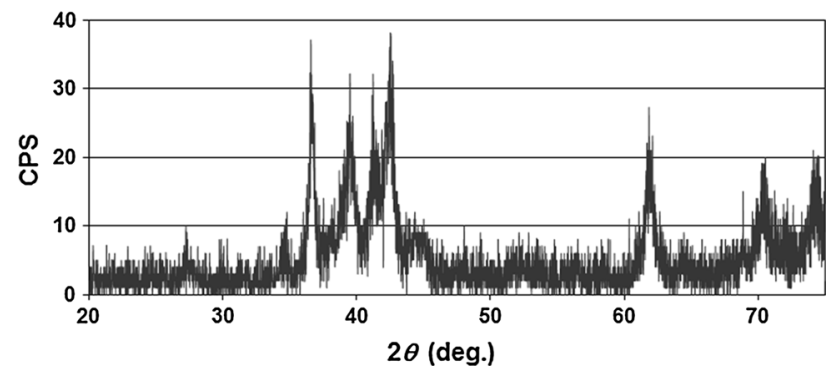

Fig. 2 XRD patterns of the transverse cross section of FSP nitrided titanium

distance of $3 \mathrm{~mm}$ under the topmost layer of the sample, the two new peaks for TiN are present. This indicates that the phase transformation involves the formation of TiN, even at a relatively large distance of $3 \mathrm{~mm}$ under the topmost surface of the sample. The above results indicate that the titanium nitride is notably penetrated through the sample.

The results clearly revealed the formation of TiN after FSP nitriding on the surface layer of the sample base. In fact, the XRD pattern shows two main Ti peaks at $2 \theta$ values of $38.3^{\circ}$ and $40.0^{\circ}$ and two peaks for TiN at $36.6^{\circ}$ and $42.7^{\circ}$. It is interesting to note that, based on XRD pattern showed in Fig. 2, after nitriding process, the intensities of new TiN peaks and the peaks of $\mathrm{Ti}$ are about the same, emphasizing more or less equal contribution of $\mathrm{TiN}$ and $\mathrm{Ti}$ at the surface after the FSP processing. Importantly, Fig. 2 shows no signal from the formation of Ti oxides.

The microstructures of the composite layer after nitriding are shown in Fig. 3. First of all, as is obvious from Fig. 3a, an excellent metallurgical bond is observed between the interface of the composite layer and the base metal. Meanwhile, a needle-like structure is formed in most areas of the TMAZ, from the top surface (Fig. 3b) through the stir zone (Fig. 3c). As can be seen, the needles have random orientations in all regions. This needle-like structures observed could be a result of formation of $\alpha^{\prime}$-titanium, due to high thermal effect. It is worth mentioning that some nitrogen molecules are likely to remain un-reacted, which can enter into the interstitial sites and, consequently, facilitate the formation of needle-like titanium martensite [18].
Figure 4 shows the SEM image of the stir zone of surface composite layer, which indicates a better view for TiN reinforcement into the Ti matrix. As observed from XRD pattern (Fig. 2) and microstructure results (Figs. 3, 4), the thickness of the surface layers formed during the new nitriding processing depends on the depth of the groove and the size of the pin tool. The experimental results of nitrided layers in the present study show that the thickness of the composite layer obtained is about $3 \mathrm{~mm}$, which is much larger than that previously reported for the similar layers formed by the diffusion and re-melting methods $[4,5,19-21]$.

Since FSP is a solid-state method, its application to nitriding process is not expected to result in the formation of dendrite shape TiN, in contrast to the case of the use of re-melting method for nitriding process $[4,6,18]$. In addition, based on the reported $\mathrm{Ti}-\mathrm{N}$ phase diagram [22], the preparation of titanium nitride by diffusion methods needs a relatively large amount of nitrogen at high temperatures and relatively long time. In fact, the temperature needed in both re-melting $[6,18]$ and diffusion [5] methods is quite high, i.e., over 1050 and up to $1670{ }^{\circ} \mathrm{C}$, while, in the case of the proposed method, the FSP at the surface of titanium under a flow of nitrogen, on the interface between the tool and the metal surface, will result in the formation of Ti/TiN composite layers in a very short period of time (a few seconds), at lower temperatures (i.e., $803{ }^{\circ} \mathrm{C}$, as measured by the procedure given in Experimental section). It should be noted that the above temperature was measured $2 \mathrm{~mm}$ below the surface of the plate, where the stir zone is located, while the real temperature on the surface should be higher. Thus, the surface temperature calculated based on a previously published method [8] was found to be $1015^{\circ} \mathrm{C}$. The surface temperature measured in a previous paper from this research group was measured as $1077^{\circ} \mathrm{C}$, using a portable infrared thermometer and a K-type thermocouple [23].

In fact, the formation of Ti/TiN layer could be explained by the creation of a high pressure between the tool shoulder and the top surface of the base material, due to the downward force provided by the tool, and the high strain rate produced by the rotating pin in the TMAZ [8]. Here, the nitrogen molecules could be trapped into the material flow during rotating and traveling of the tool. Thus, a high local temperature of $>800{ }^{\circ} \mathrm{C}$ produced from the friction of 

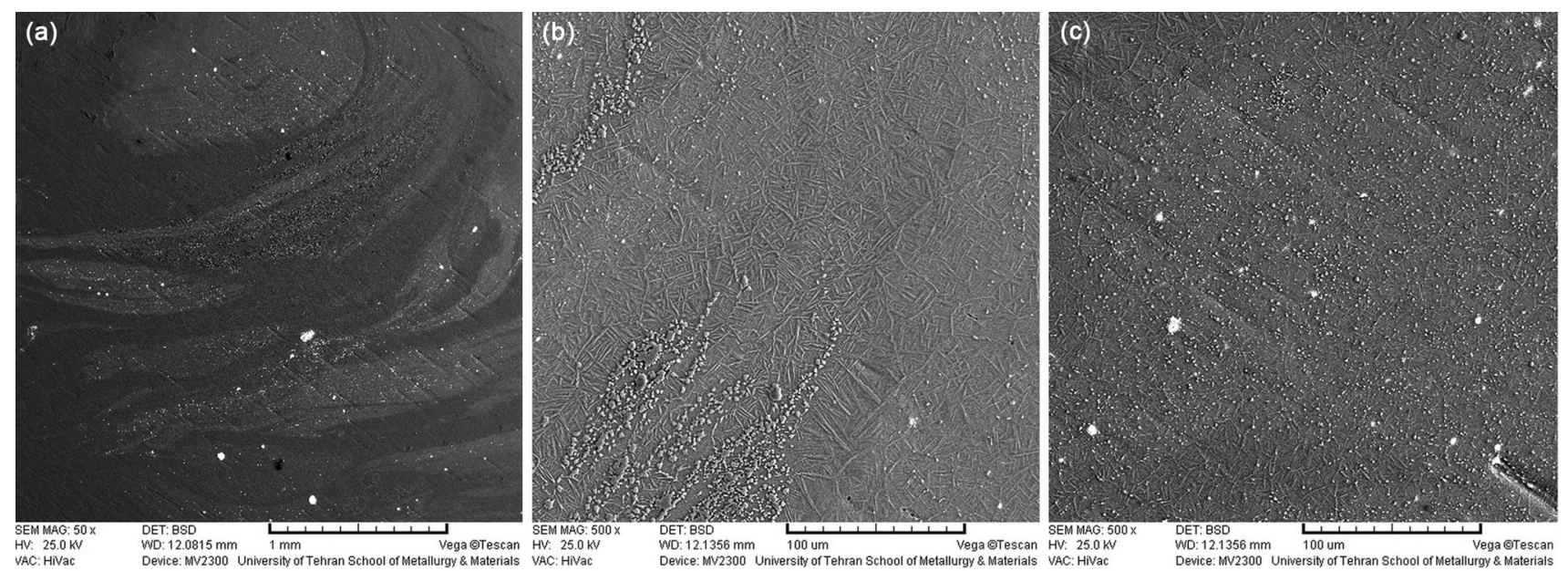

Fig. 3 SEM images of the: a stir zone, b near-surface TMAZ, $\mathbf{c}$ middle of the stir zone

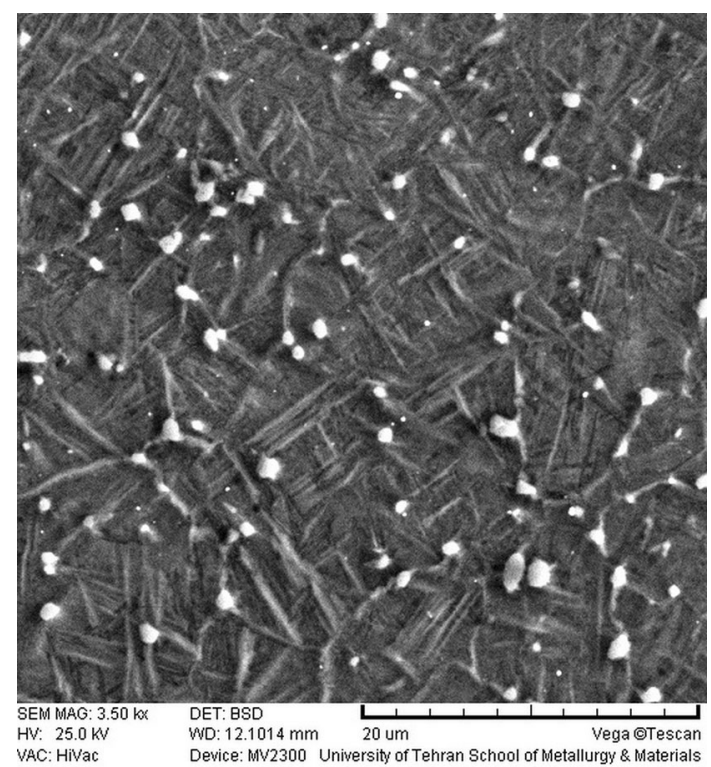

Fig. 4 SEM images of the Ti/TiN surface composite layer

tool and base metal together with the high strain rate will possibly provide the required energy for occurrence of a chemical reaction between the trapped nitrogen molecules and $\mathrm{Ti}$ substrate to produce $\mathrm{TiN}$, almost instantaneously. It is worth mentioning that titanium nitriding by diffusion methods is not only time-consuming, but also needs relatively large amount of nitrogen at high temperature [16].

\subsection{Microhardness Measurements and Wear Resistance}

Figure 5 presents the microhardness profile of Ti/TiN surface composite under flow of nitrogen gas (a) and FSPed titanium in the absence of nitrogen gas (b). As is obvious, the microhardness profile of CP-Ti after FSP pass shows an

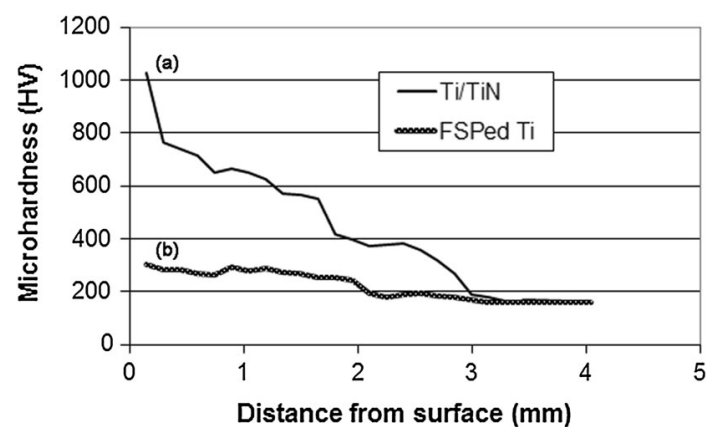

Fig. 5 Typical variation of the microhardness distributions of the surface Ti/TiN composite layers a, FSPed titanium in the absence of nitrogen $\mathbf{b}$

elevation (up to $301 \mathrm{HV}$ ) in the stirred zone, while that of the as-received substrate is only $160 \mathrm{HV}$. These observations revealed that the hardness distribution of stirred zone has been affected by grain size reduction produced by dynamic re-crystallization [8]. The result shows an increase in the microhardness after nitriding, due to the grain size reduction of the base material, brought about upon dynamic re-crystallization resulting from FSP [8], and the formation of TiN phase on the sample surface. As is quite obvious, the average microhardness of as-received titanium base metal is $160 \mathrm{HV}$. However, after fabricating the surface Ti/ TiN composite by the proposed FSP method, the microhardness is increased up to $1024 \mathrm{HV}$, which is almost 6.4 times that of the as-received material.

The variation in weight loss of untreated titanium (1), FSPed titanium in the absence of nitrogen (2) and the Ti/ TiN composite (3) as a function of load at a constant sliding speed of $0.3 \mathrm{~m} \mathrm{~s}^{-1}$ is shown in Fig. 6a. It is seen that the wear loss of all three samples increases with increasing load, the least effect in the series being observed for the Ti/TiN composite. The observed decrease in weight loss would be due to the fact that contact stress on the 

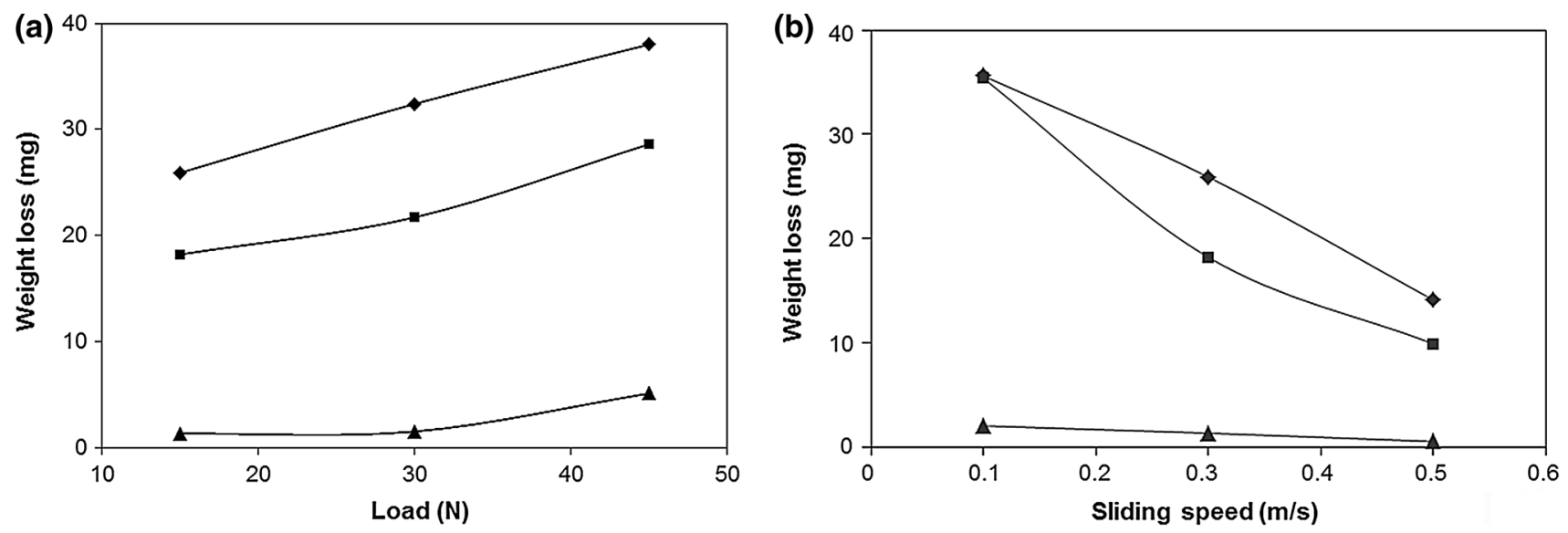

Fig. 6 a Variations in weight loss of untreated titanium (1), FSPed titanium in the absence of nitrogen (2) and Ti/TiN composite (3) as a function of load at a constant sliding speed of $0.3 \mathrm{~m} / \mathrm{s}$. b The change in weight loss for untreated titanium (1), FSPed titanium in the absence of nitrogen (2) and Ti/TiN composite (3) as a function of sliding speed under a constant applied load of $15 \mathrm{~N}$

friction surface is increased with the load, which leads to an increase in wear rate under higher load [24, 25].

Meanwhile, the change in weight loss for untreated titanium (1), FSPed titanium in the absence of nitrogen (2) and Ti/TiN composite (3) as a function of sliding speed under a constant applied load of $15 \mathrm{~N}$ is shown in Fig. $6 \mathrm{~b}$. As seen, in the cases of untreated titanium and FSPed titanium in the absence of nitrogen, the wear rate decreases significantly with the sliding speed in the range of $0.1-0.5 \mathrm{~m} \mathrm{~s}^{-1}$, while the change in weight loss of the Ti/ TiN composite with sliding speed is negligible. The wear rate of the Ti/TiN surface composite sample was $1.2 \times 10^{-5} \mathrm{~g} \mathrm{~m}^{-1}$ at a load of $30 \mathrm{~N}$, while that of the FSPed sample in the absence of nitrogen and the Ti base sample was $1.89 \times 10^{-5}$ and $1.93 \times 10^{-5} \mathrm{~g} \mathrm{~m}^{-1}$, respectively, at the same experimental conditions. Moreover, the coefficient of friction for the untreated titanium sample and the FSPed titanium is $\sim 0.54$ and that for Ti/TiN surface composite is $\sim 0.46$, which shows a considerable decrease after FSP in the presence of nitrogen gas. These results indicate an excellent wear resistance for Ti/TiN composite sample produced by the proposed method, which is attributed to the formation of $\mathrm{TiN}$ on the surface as well as the improved hardness of the composite.

The important role of wear rate and strain rate microstructural response of metals in near-surface and subsurface microstructural evolution is well documented [26]. Kailas and Biswas [27] have observed experimentally that, in the case of titanium, the wear rate reduces with the increase in sliding speed. This behavior was related to the reduction in the intensity of adiabatic shear banding (ASB), as a microstructural instability, in near-surface regions of the titanium pin, which results in flow localization and regions of crack nucleation. In fact, the observed decrease in the rate of wear with the increase in the sliding velocity
(Fig. 6b) is most probably due to the decreased intensity of shear banding, as a result of the substantial increase in the temperature near-surface region [28]. On the other hand, at relatively low sliding speeds, the intensity of adiabatic shear banding will be high in the near-surface region (Fig. 6b). Since the adiabatic shear bands are suitable sites for crack nucleation and propagation, a larger number of wear debris will be generated, which lead to a high wear rate $[27,28]$.

The XRD analyses of worn surfaces of all three samples at a sliding speed of $0.5 \mathrm{~m} \mathrm{~s}^{-1}$ were also conducted, and the results are shown in Fig. 7. As is quite obvious, during sliding, the surfaces of both Ti base and FSPed Ti samples are mainly covered by $\mathrm{TiO}_{2}$ together with some TiO. Interestingly, in the case of Ti/TiN composite, the XRD pattern shows no $\mathrm{TiO}_{2}$ at the surface with only some $\mathrm{TiO}$ present. However, $\alpha$-Ti peaks appeared in the XRD patterns of all three samples, which basically arise from the penetration of X-ray beyond the oxide layer through the $\mathrm{Ti}$

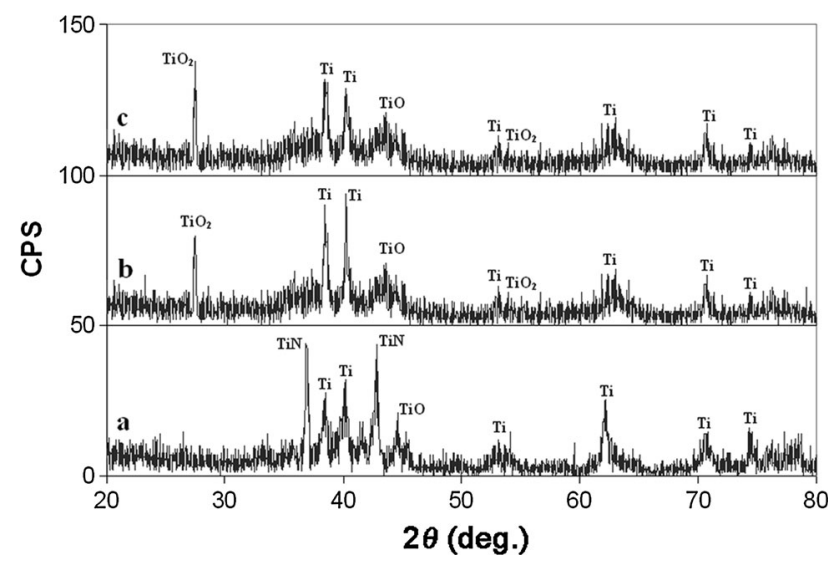

Fig. 7 XRD of worn surfaces of Ti/TiN composite $a$, FSPed titanium in the absence of nitrogen $b$ and cp-Ti samples $c$ 
matrix [29]. It is interesting to note that, according to Fig. 9a, b, the XRD peaks of titanium oxide on the worn surfaces of the cp-Ti and the FSPed Ti samples are identical, emphasizing the fact that the fine grain structure of the FSPed sample does not affect the wear products on the sample surface, so that no improvement in wear resistance was observed; this is most probably due to the dominance of oxidative wear mechanism [29]. La et al. [24] previously examined the worn surface of pure Ti via XRD analysis and found that the XRD spectra of $\mathrm{TiO}_{2}$ on the worn surface of the annealed Ti are identical to those of the ultrafine grain $\mathrm{Ti}$.

It is well known that, in dry sliding process, the increased temperature on the friction surface would significantly promote the tribochemical reactions [24]. Consequently, the worn ultra-fine grain Ti surface would easily be oxidized to form $\mathrm{TiO}_{2}$, and as a result, the worn surface is covered by the titanium oxide steadily in the course of friction and wear tests; here, the establishment of a dynamic equilibrium between the formation and removal of $\mathrm{TiO}_{2}$ will result in friction stability [24]. Thus, the increased friction surface temperature with the sliding speed results in increased amount and thickness of the $\mathrm{TiO}_{2}$ oxide, which in turn causes decreased wear of the material.

In a work dealing with the dry sliding wear behavior of Ti based on synergy between tribo-oxidation and strain rate response, Chelliah and Kailas [30] have concluded that when the temperatures of surface and subsurface are high, the microstructural response of $\mathrm{Ti}$ becomes homogeneous with increasing sliding speed so that the oxide layer protects titanium and lowers the wear rates. In fact, at lower sliding speeds, the adiabatic shear banding intensity near the surface regions is high and the oxidation rate is low. The high ASB intensity at lower sliding speeds makes the oxide layer formation become ineffective due to larger level of cracking near the surface. This makes the oxidative wear an additive phenomenon and not a protective one.

Figure $8 \mathrm{a}, \mathrm{b}$ shows the SEM images of the worn surfaces of the as-received Ti sample and the synthesized Ti/ TiN surface composite, respectively. It should be mentioned that the SEM pattern of the FSPed Ti in the absence of nitrogen is very similar to that of the as-received titanium. As can be seen, in the case of as-received Ti sample, the worn surface is quite rough with very deep plowing grooves and some debris together with a severe abrasive and adhesive wear occurred, due to the high wear rate of the sample. The EDS performed on these wear particles showed the presence of titanium (53.1 wt $\%$ ), iron (6.47 wt $\%)$ and oxygen $(40.43 \mathrm{wt} \%)$, the presence of some

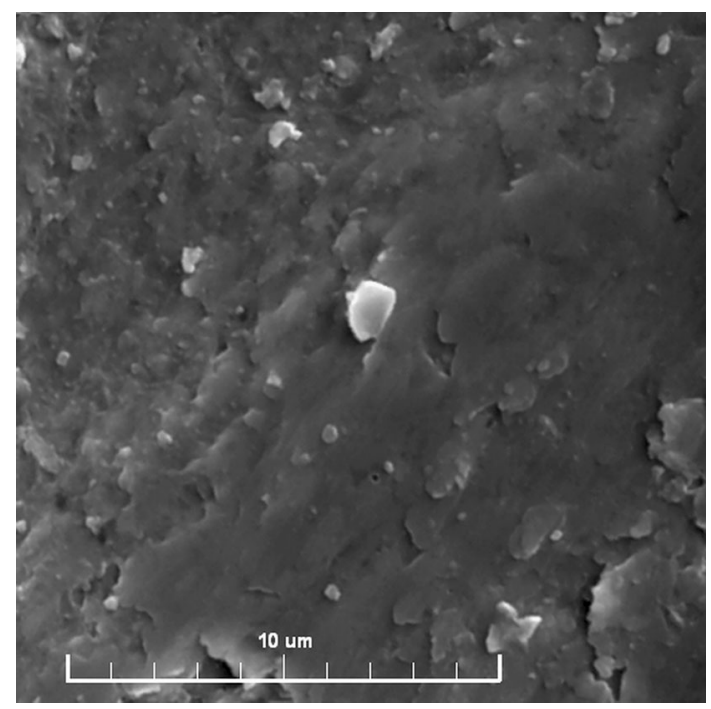

Fig. 9 SEM image of the Ti wear debris

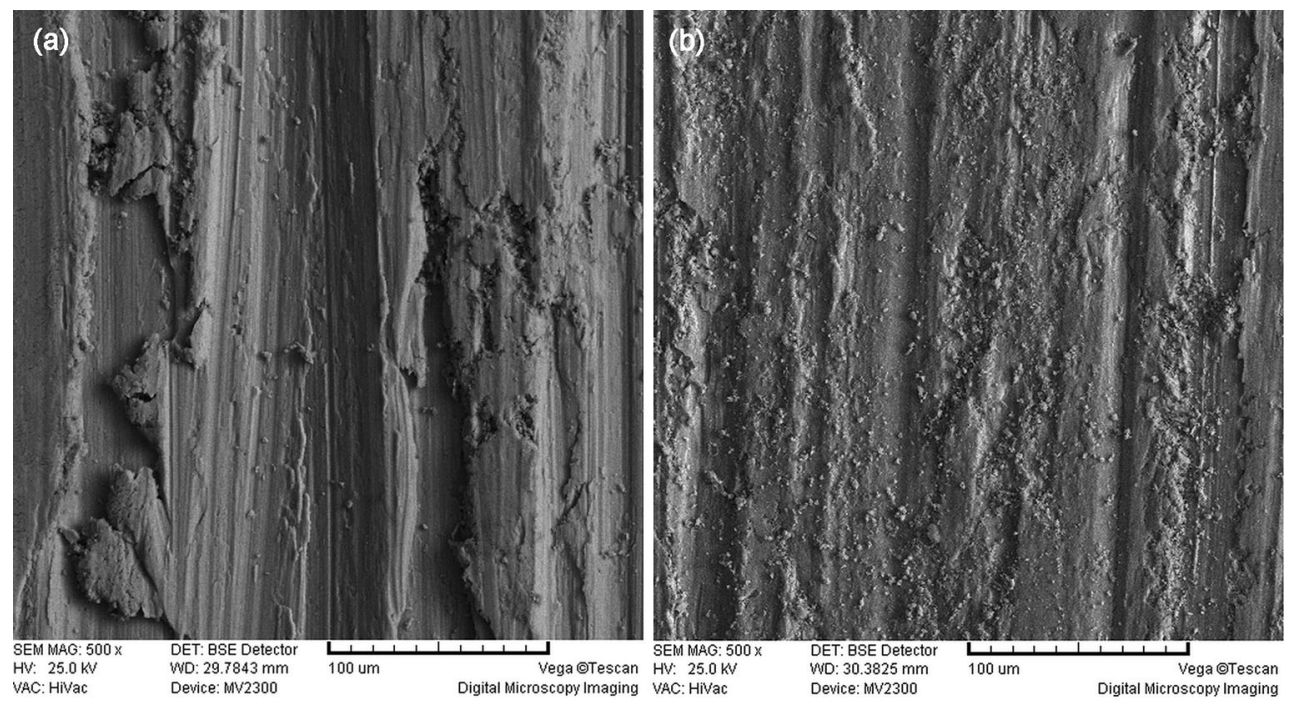

Fig. 8 SEM images of the worn surfaces of the as-received Ti sample a and the Ti/TiN surface composite $\mathbf{b}$ 
Table 1 Comparison of different titanium nitriding methods

\begin{tabular}{|c|c|c|c|c|c|c|}
\hline Method & Process time & Process temperature $\left({ }^{\circ} \mathrm{C}\right)$ & $\begin{array}{l}\text { Layer thickness } \\
(\mu \mathrm{m})\end{array}$ & $\begin{array}{l}\text { Microhardness } \\
(\mathrm{HV})\end{array}$ & $\begin{array}{l}\text { Friction } \\
\text { coefficient }\end{array}$ & References \\
\hline Laser nitriding & $\begin{array}{l}\text { A few } \\
\text { minutes }\end{array}$ & $2300-4300$ & 400 & 2700 & $0.4-0.6$ & [7] \\
\hline Gas nitriding & $1-10 \mathrm{~h}$ & $950-1050$ & 30 & 800 & - & {$[5]$} \\
\hline Plasma nitriding & $3-9 \mathrm{~h}$ & $400-800$ & 0.5 & - & $0.1-0.5$ & [21] \\
\hline $\begin{array}{l}\text { Reactive FSP } \\
\text { nitriding }\end{array}$ & $\begin{array}{l}\text { A few } \\
\text { seconds }\end{array}$ & $\begin{array}{l}\text { 803, in stir zone, and 1015, at } \\
\text { surface }\end{array}$ & 3000 & 1024 & 0.46 & This work \\
\hline
\end{tabular}

iron being from the steel disk. These results indicated that a large amount of oxide can be produced during the wear testing of the titanium sample. It is noteworthy that the XRD pattern (Fig. 2b) as well as EDS of the sample before wear test showed no iron-containing phase.

In order to have a better understanding of the resulting debris on worn surface of titanium, an SEM image of the Ti wear debris was obtained and shown in Fig. 9. The debris on the worn surface include both titanium oxide and mostly titanium that has fractured and came out from the surface. It should be noted that, due to charging, the $\mathrm{TiO}_{2}$ species formed at the worn surfaces show brighter patterns than the metallic titanium, although they have a smaller population than the Ti debris. Interestingly, the titanium debris has laminar shapes, resulting from the cracks generated via adiabatic shear banding.

The observation of the deep scratches and grooves on the worn surface of cp-Ti (Figs. 8, 9) could be related to its abrading via the hard debris particles in the form of $\mathrm{TiO}_{2}$ as well as the asperities of mating surfaces. Here, some of the debris particles could be entrapped between the mating surfaces and abrade the sample surface during sliding [29].

On the other hand, less abrasive wear tracks were observed on the worn surface of the Ti/TiN composite, compared to the as-received Ti sample. Also, the amount and depth of plowing grooves of the composite sample (ave. $\mathrm{Ra}=3.5 \mu \mathrm{m}$ ) are lower than those of the cp-Ti sample (ave. $\mathrm{Ra}=5.1 \mu \mathrm{m}$ ). The morphology of the worn surface shows the presence of large number of debris. The EDS result shows the presence of titanium (62.02 wt $\%$ ), iron (7.99 $\mathrm{wt} \%)$ and oxygen (30.99 $\mathrm{wt} \%$ ) revealing that the oxidation during the wear testing of $\mathrm{Ti} / \mathrm{TiN}$ sample is decreased, due to the fabrication of the TiN phase. In this case, the sliding wear of $\mathrm{Ti} / \mathrm{TiN}$ composite can be described by the formation of debris and materials transfer.

\subsection{Comparison with Other Methods}

Table 1 shows a comparison of the experimental conditions, layer thickness and some mechanical properties of the $\mathrm{Ti} / \mathrm{TiN}$ surface composites prepared in this work and those reported by other methods such as gas nitriding [5], laser nitriding [7] and plasma nitriding methods [21]. As is obvious from Table 1, at much lower process time and a surface temperature of $1015^{\circ} \mathrm{C}$, the proposed reactive FSP nitriding results in much higher layer thickness with more or less similar microhardness and friction coefficients.

\section{Conclusion}

In this work, the $\mathrm{Ti} / \mathrm{TiN}$ surface composite layers were prepared via FSP under blowing nitrogen gas. The nitrogen gas reacted with titanium substrate due to the high local temperature and pressure created by FSP in the stir zone and resulted in the formation of a 3-mm-thick Ti/TiN composite layer. The resulting $\mathrm{Ti} / \mathrm{TiN}$ composite was characterized by microstructure analyses, hardness and wear tests. The maximum microhardness of the Ti/TiN composite reached $1024 \mathrm{HV}$, which is 6.4 times higher than that of the titanium substrate. The resulting Ti/TiN composite layer showed excellent abrasive and adhesive wear resistance. A comparison of the experimental conditions, layer thickness and some mechanical properties of the Ti/TiN surface composites prepared in this work and those reported by other methods, such as gas nitriding, laser nitriding and plasma clearly reveled that, at much lower process time and a surface temperature of $1015^{\circ} \mathrm{C}$, the proposed reactive FSP nitriding results in much higher layer thickness with more or less similar microhardness and friction coefficients.

\section{References}

[1] C. Leyens, M. Peters (eds.), Titanium and Titanium Alloys: Fundamentals and Applications (Wiley-VCH, Weinheim, 2003)

[2] R. Boyer, G. Welsh, E.W. Collings, Materials Properties Handbook-Titanium Alloys (ASM International, Materials Park, 1994)

[3] V. Gorynin, Mater. Sci. Eng. A 263, 112 (1999)

[4] A. Zhecheva, W. Sha, S. Malinov, A. Long, Surf. Coat. Technol. 200, 2192 (2005) 
[5] A. Zhecheva, S. Malinov, W. Sha, Surf. Coat. Technol. 201, 2467 (2006)

[6] E.C. Santos, M. Morita, M. Shiomi, K. Osakada, M. Takahashi, Surf. Coat. Technol. 201, 1635 (2006)

[7] M.S.F. Lima, F. Folio, S. Mischler, Surf. Coat. Technol. 199, 83 (2005)

[8] R.S. Mishra, Z.Y. Ma, Friction stir welding and processing. Mater. Sci. Eng. R 50, 1 (2005)

[9] M. Barmouz, M.K. Besharati-Givi, J. Seyfi, Mater. Charact. 62, 108 (2011)

[10] R. Sathiskumar, N. Murugan, I. Dinaharan, S.J. Vijay, Mater. Character. 84, 16 (2013)

[11] A. Shamsipur, S.F. Kashani-Bozorg, A. Zarei-Hanzaki, Surf. Coat. Technol. 206, 1372 (2011)

[12] C.J. Lee, J.C. Huang, P.J. Hsieh, Scr. Mater. 54, 1415 (2006)

[13] A. Shafiei-Zarghani, S.F. Kashani-Bozorg, A. Zarei-Hanzaki, Mater. Sci. Eng. A 500, 84 (2009)

[14] Y. Morisada, H. Fujii, T. Nagaoka, M. Fukusumia, Scr. Mater. 55, 1067 (2006)

[15] Y. Morisada, H. Fujii, T. Nagaoka, M. Fukusumia, Mater. Sci. Eng. A 419, 344 (2006)

[16] Y. Morisada, H. Fujii, T. Nagaoka, M. Fukusumia, Mater. Sci. Eng. A 433, 50 (2006)

[17] A. Shamsipur, S.F. Kashani-Bozorg, A. Zarei-Hanzaki, Surf. Coat. Technol. 218, 62 (2013)
[18] S. Mridha, J. Mater. Proc. Technol. 168, 471 (2005)

[19] W. Sha, M.A. Haji, M. Don, A. Mohamed, X. Wu, B. Siliang, A. Zhecheva, Mater. Charact. 59, 229 (2008)

[20] Z.D. Cuia, S.L. Zhua, H.C. Manb, X.J. Yanga, Surf. Coat. Technol. 190, 309 (2005)

[21] M.P. Kapczinski, C. Gil, E.J. Kinast, C.A. Santos, Mater. Res. 6, 265 (2003)

[22] T.B. Massalski, H. Okamoto, P.R. Subramanian, L. Kacprzak (eds.), Binary Alloy Phase Diagrams, 2nd edn. (ASM International, Materials Park, 1990)

[23] M. Fazel-Najafabadi, S.F. Kashani-Bozorg, A. Zarei-Hanzaki, Mater. Des. 31, 4800 (2010)

[24] P.Q. La, J.Q. Ma, Y.T. Zhu, J. Yang, W.M. Liu, Q.J. Xue, R.Z. Valiev, Acta Mater. 53, 5167 (2005)

[25] S. Hogmark, S. Jacobson, O. Vingsbo, Metals Handbook, 10th edn. (ASM International, Metals Park, 1990)

[26] S.V. Kailas, J. Mater. Eng. Perform. 12, 629 (2003)

[27] S.K. Biswas, A.V. Kailas, Tribol. Int. 30, 369 (1997)

[28] A.V. Kailas, S.K. Biswas, J. Tribol. 119, 31 (1997)

[29] G. Purceka, O. Saraya, O. Kula, I. Karamanb, G.G. Yapici, M. Haouaouib, H.J. Maierc, Mater. Sci. Eng. A 517, 97 (2009)

[30] N. Chelliah, A.V. Kailas, Wear 266, 704 (2009) 